Bartın Üniversitesi

Eğitim Fakültesi Dergisi

Cilt 5, Sayı 2, s. 608 - 616, Haziran 2016 BARTIN - TÜRKIYE

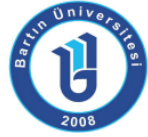

ISSN: 1308-7177
Bartin University

Journal of Faculty of Education

Volume 5, Issue 2, p. 608 - 616, June 2016

BARTIN - TURKEY

Doi: 10.14686/buefad.v5i2.5000190535

\title{
Öğretmen Yetiştirme ve İngilizce Bölüm Öğrencilerinin İstihdama iliş̧in Düşünceleri: Nitel Bir Çalışma
}

İrfan TOSUNCUOĞLU, Yrd. Doç. Dr., Karabük Üniversitesi, Edebiyat Fakültesi, irfantosuncuoglu@karabuk.edu.tr

Öz: Çalışmada öğretmen yetiştirme konusu ele alınmış, İngilizce Bölüm mezunlarının istihdamına ilişkin düşünceleri de nitel bir çalışmayla belirlenmiştir. Araştırmada nitel bir yöntem ve durum çalışması kullanılmıştır. Nitel durum çalışmaları bir ya da birkaç durumun detaylı bir şekilde araştırımasıdır. Araştırma çalışma grubunu, Karabük Üniversitesi İngiliz Dili ve Edebiyatı Bölümünde öğrenim gören yirmi bir dördüncü sınıf öğrencisi oluşturmaktadır. Çalışmada kolay ulaşılabilir örnekleme yapılarak gönüllü öğrencilere yönelik uygulama yapılmıştır. Öğrenciler bölüme gelmelerinden itibaren gelecekleriyle ilgili endişe duymaktadırlar ve Edebiyat Fakültesinde Filoloji Eğitimi almalarına rağmen mezun olunca istihdam kaygılarından dolayı Pedagojik Formasyon Sertifikası Eğitimi almak istemektedirler. Bugün on binlerce öğretmen adayı atama beklemektedir. Okullardaki öğretmen ihtiyacı atama kontenjanlarının sınırlı olması nedeniyle, yarı zamanlı ya da ücretli kategorisindeki öğretmenlerle sağlanmaya çalışılmaktadır.

Anahtar Kelimeler: İngilizce bölümü, öğrenci, istihdam, öğretim, pedagojik formasyon.

\section{Teacher training and Ideas of the Students of English Department about Employment: A Qualitative Study}

Abstract: In this study teacher training was mentioned, ideas of the graduate students of English Departments were defined by means of a qualitative study. It was used a qualitative method and case study in the work. The qualitative case study is the research of one or more cases in details. The study group of the research is twenty one undergraduate students of English Language and Literature Department, Karabuk University. It was done easy reachable exemplification and the application was directed towards voluntary students. The students worry about their future just after the registration for the department and although they study at the Philology Department they want to have Pegagogical Formation Certificate to teach so that they will have an anxiety problem of unemployment after graduation. Today ten thousands of the teacher candidates wait for appointment by the state. Because of limited appointment vacancies, the schools try to provide the teacher needs with part time or paid teachers.

Key Words: English Department, student, employment, teaching, pedagogical formation. 


\section{GíRiş}

Günümüzde, uluslararası siyasi, iktisadi, ticari ve kültürel ilişkilerin gittikçe artmasıyla yabancı dil bilgisi ve eğitimi diğer ülkeler için olduğu kadar bizim içinde önemli bir gereksinim haline dönüşmüştür. Bu nedenle iyi veya ileri seviyede en az bir yabancı dil bilen nitelikli bireyler yetiştirmek son derece önemlidir. En az bir yabancı dil bilen nitelikli bireyler yetiştirebilmek için öğretim sisteminin görevi, mesleki yönden son derece iyi bilgi ve beceriye sahip, devamlı olarak kendisini geliştirme ve yenileme çabası içinde olan, mesleğini öğretimde özgüveni son derece yüksek yabancı dil öğretmenleri yetiştirmek olmalıdır.

Eğitim sisteminin odak noktasında ilk sırada öğretmenler yer almaktadır. Eğitim ve öğretim alanındaki hedeflere öğretmenler ve öğretmen adaylarının nitelikli katkılarıyla ulaşılır. Öğretmenin mesleki açıdan yeterliliği, kişiliği ve öğrencilere karşı yaklaşımı, tutumu çok önemlidir (Ensari, 2000, 85, Akt, Atmaca, 2013). Bu nedenle öğretmenin niteliği de, eğitim sistemindeki çıktı seviyesini yükseltmede temel ve değişmez bir unsurdur.

Eğitimin her kademesinde ders içeriklerinin verimli bir biçimde öğrenilebilmesinin öğrencilerin düşünme işlevlerini etkin bir biçimde kullanmalarından geçtiği; bu şekilde yapmadıkları takdirde ezbere yönelecekleri ifade edilmektedir (Paul ve Elder, 2001). Bireylerin eleştirel düşünme düzeylerinin yüksek olması, eğitimde beklenen sonuçlardan biridir (Halpern, 1993; Hudgins ve Edelman, 1988: Akt. Semerci, 2000). Ennis'e (1991) göre, öğretmen eleştirel düşünme becerisi kazandırmada en önemli unsurdur. (Akt. Abazaoğlu, 2014). Öğrencilerin kendilerine aktarılan bilgileri çözebilmesi gerekmektedir (Brad, 1994).

Çeliköz ve Çetin'de (2004) öğretmen adaylarının meslek hayatlarına başlamadan önce meslekleri için olumlu bir davranış geliştirdiklerinde, çok başarılı bir öğretmen olabileceklerini belirterek, derslerde daha etkin, daha verimli olacaklarını ve öğrencileri rahatlıkla motive edebileceklerini ifade etmişlerdir.

Ülkemizde İngilizce'nin yabancı dil olarak öğretilmesinin popüler olması Eğitim Fakültelerinde bulunan yabancı dil eğitim programlarına da kademeli olarak yansımıştır. 1997 yılında yapılan eğitim reformuyla eğitim ve öğretim programına küçük yaşta öğrencilere Ingilizce öğretimi dersleri girmiştir. 2015 ve 2012 yılları arasında yapılan reformların yanı sıra Yüksek Öğretim Kurumu (YÖK) tarafından tavsiye edilen öğretmen eğitimi müfredatlarında da yine küçük yaştaki çocuklara Dil öğretilmesine yönelik dersler müfredata programına eklenmiştir. (Bayyurt ve Akcan, 2014). Öğretmenin esas görevi, öğrenme sürecindeki her seviyedeki öğrenciye rehberlik edip yol göstererek öğrenmenin daha kolaylaştırılasını sağlamaktır.

\subsection{Cumhuriyetin Kuruluşundan Günümüze Öğretmen Yetiştirme}

Cumhuriyetin kuruluşundan günümüze kadar geçen zaman dilimine bakıldığında ülkemizde öğretmen yetiştirme konusunda farklı yollar ve teknikler uygulandığı görülmektedir. Öğretmen yetiştirme konusunda; ilk olarak Öğretmen Okulları, Köy Enstitüleri ve sonrasın da ise Yüksek Öğretmen Okullarının açılmıştır (Uygun, 2010). Türkiye'de eğitim hizmeti, merkezi bir sistemle olmaktadır; ilk, orta ve liselerde eğitim ve öğretim faaliyetleri ve organizasyonu Milli Eğitim Bakanlığı(MEB) tarafından yürütülür. Cumhuriyetin kuruluşundan 1980'li yıllara kadar olan zaman diliminde öğretmen yetiştirme ve istihdamları MEB'in yetki ve sorumluluğunda altında olmuştur. 1981 yılına ise, öğretmen eğitimi üniversitelere bırakılmıştır.

1990'lı yılların sonlarına doğru öğretmen ihtiyacına yönelik dikkate değer bir kadro artışı olmuştur, bu durum intiyaçla doğru orantılı bir biçimde gerçekleşmiştir. 2000'li yıllara gelindiğinde ise Eğitim Fakültelerinde öğrenim gören öğrenci sayılarında büyük bir artış yaşanmadığını görmekteyiz. Bu bağlamdaki diğer bir nokta ise Eğitim Fakültelerine nazaran, 
çok istihdam alanı bulunmayan, Fen Edebiyat Fakültelerinin öğrenci kontenjanlarında kayda değer bir artışın olduğunu görmekteyiz. Araştırmalarımızın neticesinde 2000-2009 yılları arasında Eğitim Fakültelerinin kontenjanları \%16,5, buna karşın Fen Edebiyat Fakültelerinin kontenjanlarında ise \%72 gibi bir artış görülmüştür. Açık Öğretim Programları hariç, en fazla kontenjan artışının Fen Edebiyat Fakültelerinde olduğunu gözlemlemekteyiz. Fen Edebiyat Fakültesini bitiren öğrencilerin özel ve devlet sektöründe iş bulma alanları kısıtlı olduğu için ve bu fakültelerden ihtiyaçtan fazla mezun verilmesi sebebiyle Yüksek Öğretim Kurumu (YÖK), Eğitim Fakültesi mezunu olmayan öğrencilere Formasyon Eğitimi verilmesi konusuna sıcak bakmıştır. Nevar ki bu durum, istihdamda planlamayı sürekli olarak sekteye uğratmıştır (Özoğlu, 2010).

\section{2. Öğretmen İstihdam Problemleri}

1995 yılından sonra öğretmen istihdamı konusunda sorunlar yaşanılmaya başlanmıştır. Bu yıllarda dört yıllık herhangi bir fakülte mezunu olan ve isteyen her mezunun sınıf öğretmeni olarak ataması yapılmıştır. Bu durum, eğitim ve öğretimin kalitesini düşürmüş, izleyen yıllarda ise öncelikli olarak sınıf öğretmenliği branşlarında kadroların şişmesine ve mezun olmuş öğretmen adaylarının istihdamlarında zorluklara neden olmaya başlamıştır.

2000 'li yıllara geldiğimizde ise öğretmen atamaları için Kamu Personeli Seçme Sınavları (KPSS) uygulanmaya başlanmıştır. Bu durum üniversitelerin son sınıflarında okuyan öğrencilerin ve mezun olup yıllarca atama bekleyen öğretmen adaylarının endişelenmelerine neden olmuştur. Buna ek olarak, Eğitim Fakültesi haricinde, Pedagojik Formasyon Eğitiminin Fen Edebiyat Fakültesi mezunlarına da verilmesi ve öğretmen atamalarının yapılıyor olması, atama bekleyen Eğitim Fakültesi mezunlarının istihdamlarını daha da güçleştirmiştir.

Özel okul ve dershaneler Eğitim Fakültesi mezunlarının istihdam edildikleri diğer kurumlardır. Ancak bu kurumlar, temel dersler için emekli ve tecrübeli öğretmenleri tercih etmektedirler. Yeni mezun öğretmenler, asgari ücretle çalıştırılmalarının yanı sıra verimli bulunmadıkları takdirde de işlerine son verilmektedir. (Yıldız, 2005, 101). Bundan başka Ingilizce Bölümlerinden mezun öğrenciler, Bankacılık, Kambiyo, Tercümanlık ve Turizm vb. alanlarda iş bulabilmektedirler. Ancak Mezun öğrencilerin büyük çoğunluğu, çalışma ortamının rahat, daimi iş garantisinin olması ve sosyal haklarının iyi olması nedeniyle kamu sektörünü tercih etmektedirler.

MEB'in ihtiyacından fazla öğretmen adayının olması nedeniyle bu durum öğretmenleri çeşitli özel eğitim kurumları sektörlerinde çalışmaya mecbur etmiştir. Öğretmen adaylarımızın büyük çoğunluğu, özel sektörde nispeten düşük ücretle, zaman zaman sosyal haklardan yoksun, iş garantisi olmaksızın, az ücret karşılığında ve gereğinden daha çok çalıştırıldıklarını düşündükleri için özel sektörde çalışmak istememektedirler. Öğretmen adaylarının öncelikli hedefi Milli Eğitim Bakanlığı'nda kadrolu öğretmen olabilmektir.

\section{3. İngilizce Öğretmeni Olmak: Eğitim ve Edebiyat Fakülteleri}

Günümüz eğitim sistemi içinde İngilizce öğretmeni olmanın iki yolu vardır. Eğitim Fakültelerinin İngiliz Dili Eğitimi Bölümü veya Edebiyat Fakültelerinin İngilizce Bölümlerinden mezun olarak Lisans Diploması almak. Edebiyat Fakültelerinin İngiliz Dili ve Edebiyatı programlarında öğrenim gören öğrenciler, akademik programları boyunca Grammar (Grammar), Reading and Textual Analysis (Metin Okuma ve İnceleme), Linguistics(Linguistik) gibi dil beceri derslerinin yanında, Introduction to Literature(Edebiyata Giriş), Mytology(Mitoloji), Short Stories (Kısa Hikâyeler) gibi derslerle daha çok Edebiyat ağırlıklı bir eğitim almaktadırlar. Ancak Formasyon eğitimi alan öğrenciler Eğitim Bilimine Giriş, Eğitim Psikolojisi, Türk Eğitim Tarihi, vb., dersleri almaktadır. Edebiyat Fakültelerinin İngiliz Dili ve 
Edebiyatları bölümlerde okuyan öğrenciler Eğitim Fakültelerinde olduğu gibi İngilizce öğretimiyle ilgili geniş çapta dersler almamaktadırlar, ayrıca Eğitim Fakültelerindeki eğitimle ilgili dersler son yıllarda ihtiyaca göre güncellenmiştir.

Inal'a (2015) göre Eğitim Fakültelerinde uygulanan revize edilmiş programlar 2006 yılından bu yana İngilizce ve ilgili dünyadaki değişiklikleri kapsayan programlardır. YÖK yeni programlardaki derslerin bazılarının açıklamalarında gelecekte öğretmen olacak olan öğrencilerin dünyadaki değişen değerlerden ve fikirlerden haberdar olmalarını, İngilizceye "kültürlerarası iletişim, gibi konular çerçevesinde bir bakış açısıyla bakmalarını istemekte ve bu bakış açısını İngilizce derslerine de yansıtmalarını hedeflemektedir.

Eğitim Fakültelerinin ilgili bölümlerini bitirenler, Lisans eğitimleri sırasında Eğitim Bilimlerine yönelik gerekli öğretmenlik (pedagojik) Formasyon dersleri aldıkları için mezuniyet sonrası yeterli puan aldıkları takdirde hemen atanabilmekte, kamu veya özel sektörde iş bulma olanağına sahiptirler. Edebiyat Fakültesi mezunları ise son sınıfta veya mezuniyet sonrasında bir yıl süren Pedagojik Formasyon programını bitirerek, belirli bir ücret karşılığında eğitici sertifikası almaları gerekmektedir. Bu yüzdendir ki, Edebiyat Fakülteleri, İngiliz Dili ve Edebiyatı öğrencileri birinci sınıfa başladığı andan itibaren mezuniyetlerine kadar olan eğitim sürecinde mesleki kaygı içinde eğitimlerini devam ettirmektedirler. Bu olumsuz süreç öğrencilerin bu bölüme dönük motivasyonlarını azaltmaktadır. Başlangıçta motivasyonlarının az olmasına rağmen ileri yıllarda olumlu yönde gelişme göstermekte ise de, yine de öğrencilerin atamalarına kadar uzanan süreçte iş bulamama endişe ve korkusu aşılamamaktadır.

\section{ARAŞTIRMANIN AMACI}

Araştırmanın amacı İngilizce Bölüm mezunlarının istihdamına ilişkin düşüncelerinin nitel bir çalışmayla belirlenmesidir. Bu amaç kapsamında aşă̆ıdaki sorulara cevap aranmıştır;

1. İsdihdamla ilgili sorunlar nelerdir?

2. İsdihdamla ilgili beklentiler nelerdir?

3. Öğretmen olmak istiyor musunuz?

\section{YÖNTEM}

Araştırmada nitel bir yöntem kapsamında durum çalışması kullanılmıştır. Nitel durum çalışmalarında bir ya da birkaç durumun detaylı biçimde araştırılması yapılmaktadır. Yani bir duruma ilişkin faktörler (bireyler, ortam, süreçler, olaylar, vb.) bütüncül olarak araştırılır ve ilgili durumu nasıl etkiledikleri, nasıl etkilendikleri ortaya çıkarılır (Yıldırım ve Şimşek, 2013). Öğrenciler mezun olduktan sonra istihdamlarına dönük derinlemesine, ayrıntılı bilgilere sahip değildirler. Bu nedenle durum çalışması kullanıımıştır.

\section{1. Çalışma Grubu}

Araştırma çalışma grubunu, Karabük Üniversitesi İngiliz Dili ve Edebiyatında okuyan, yirmi bir dördüncü sınıf öğrencisi oluşturmaktadır. Araştırmada kolay ulaşılabilir örnekleme yapılarak gönüllü öğrencilere uygulama yapılmıştır. Öğrencilere "Bölümü bitirince karşılaşabileceğiniz istihdam problemleri nelerdir?", sorusu sorularak toplanan dokümanların analizi yapılmıştır. Öğrencilerden toplanan dokümanlara Ö1, Ö2, Ö3, ... Ö21 olarak kod verilmiştir. Öğrencilerden $5^{\prime} \mathrm{i}$ erkek 16 'sı kızdır. Öğrencilere istihdamlarına ilişkin genel bir soru sorulmuş olup analizler iki tema altında yapılmıştır. Bu temalar, "istihdamla ilgili sorunlar ve istihdamla ilgili beklentilerdir". Bu araştırma Karabük Üniversitesi son sınıf öğrencileriyle sınırlandırılmıştır. 


\section{BULGULAR}

Bulgular, sorunlar ve beklentiler olmak üzere iki boyutta ele alınmıştır. Öğrenciler nitel cevaplarını 4'ü İngilizce olarak, 17'si de Türkçe olarak yazmıştır.

\section{1. İstihdamla ilgili Sorunlara i̇lişkin Bulgular}

Öğrenciler istihdamla ilgili sorunlarda genel olarak bölümde verilen eğitimin yetersiz olduğunu vurgulamaktadır. Ö4 kodlu öğrenci şu şekilde durumu belirtmiştir.

"Öğrenciler, okulda verilen eğitimin yetersiz olduğunu vurgulamaktadır. Hocalar çok fazla bilgi vermeden, bizden fazlasını istiyorlar" Ö4.

21 öğrenciden 3 öğrenci bir sorun belirtmezken 17 öğrenci, öğrencilerle ilgilenilmediğini, hocanın masaya oturup kitaptan okuduğunu veya slaytı açıp okuyun dediğini belirtmişlerdir. Ancak bir öğrenci bölümün verdiği eğitimin yeterli olduğunu vurgulamıştır.

\section{2. İstihdamla ilgili Beklentilere iliş̧kin Bulgular}

Öğrencilerin beklentilerinin genel olarak sınırlı olduğu görülmektedir. Beklentilere ilişkin betimsel analizle oluşturulan tablo aşağıda verilmiştir:

Tablo 1.

\begin{tabular}{lc}
\hline Istihdamla ilgili Beklentiler & \\
\hline Beklentiler & Sayı \\
Öğretmenlik (Devlette) & 13 \\
Öğretmenlik (Özel sektörde) & 3 \\
Akademisyenlik & 4 \\
Fikrim yok & 1 \\
Toplam & $\mathbf{2 1}$
\end{tabular}

Tablo 1 de, öğrencilerin genel olarak beklentilerinin devlette öğretmenlik yapmak oldukları görünmektedir. Bunun gerekçesi olarak, öğretmenliğe garanti iş gözüyle bakılmasıdır. Öğrenciler, Pedagojik Formasyon kurslarının düzenli olarak verilmesini arzu etmektedirler. Bu öğrencilerden Ö5 kodlu öğrenci şu şekilde belirtmektedir.

"Ben devlette İngilizce Öğretmeni olmak istiyorum. Devlette olmak istiyorum çünkü daha rahat. Özelde daha çok çalışııı daha az maaş veriliyor. Devlette hem maaş daha iyi ek derslerle birlikte hem de daha fazla tatil veriliyor" ö5.

Ö17 kodlu öğrenci de şu şekilde fikir beyan etmiştir:

“Normalde İngiliz Dili ve Edebiyatından mezun olan herkes özellikle formasyon alan her birey öğretmenliği tercih ediyor. Devlette olmanın birçok avantajı var. Maaş düzenli ve tatil olanakları daha fazla. Ama özel sektörde bir garanti yok. Ve bu yüzden devlette olmak her zaman bir adım önde gibi. Bu yüzden kesinlikle devlette öğretmenlik tercihimdir” Ö17.

Öğrencilerin bir kısmı da özel sektörde çalışmak istemekte ve bir kısmı ise akademisyen olmak istemektedir. Ö21 kodlu öğrenci, kendi ifadesiyle şu şekilde yorum yapmıştır:

“ingiliz Dili ve Edebiyatı, lise hayatım boyunca ilgimi çeken bir bölümdü. İsteyerek tercih yapıp bu bölüme isteyerek geldim. illk zamanlarda zorlansamda zamanla alışım. Illgimi çeken pek çok dersi çok iyi hocalarla öğrenme fırsatı yakaladım. Bu anlamda kendi bölümüm adına okulumdan memnun kaldım. Bu bölümün bana çok şey kattığını düşünüyorum. Edebi alanda kendimi geliştirmeye devam etmek ve gelecekte de edebiyat ile ilgilenmek isterim. Bu yüzden akademisyen olmak ve İngiliz Dili ve Edebiyatı alanında çalışmalar yapıp edindiğim bilgileri öğrencilerim ile paylaşmayı çok isterim" Ö21. 
Öğrencilerden sadece biri, bir fikri olmadığını belirtmiştir. Hiç düşünmediğini ve herhangi bir yorum yapamadığını söylemiştir.

Genel anlamda öğrenciler gelecekleriyle ilgili endişe duymaktadır ve Edebiyat Fakültesinde Filoloji Eğitimi almalarına rağmen mezun olunca istihdam kaygılarından dolayı Pedagojik Formasyon Sertifikası eğitimi almak istemektedirler.

\section{SONUÇ, TARTIŞMA VE ÖNERILER}

Araştırmada, İngiliz Dili ve Edebiyatı Bölümü mezunlarının istihdamına ilişkin düşüncelerinin nitel bir çalışmayla belirlenmesi amaçlanmıştır. Öğrenciler gelecekleriyle ilgili endişe duymaktadır. Edebiyat Fakültesinde Filoloji Eğitimi alan öğrencilerin büyük bir çoğunluğu Pedagojik Formasyon Sertifikası eğitimi almak istemektedirler, bunun başlıca nedeni ise mezun olduklarında öğretmen olarak iş bulabileceklerini düşünmeleridir. Ayrıca öğrenciler, bölümde verilen eğitimin yetersiz olduğunu vurgulamaktadırlar. Okuldaki öğretim üyelerinin kendileriyle daha fazla ilgilenmelerini istemektedirler. Eğitim ve öğretim sisteminde öğretmenlerin birinci hedefi nitelikli öğrenciler yetiştirmektir. Bunun içinde öğretmen adaylarının mesleki alanda yeterli bilgi ve beceriye sahip olmaları ve bu bilgi, beceriyi en iyi şekilde öğrencilere aktarabilmeleri gerekmektedir. Bu doğrultuda da üniversitelerin stratejik hedeflerinin arasında eğitimin kalite ve niteliğini arttırmak olmalıdır.

Öğretmen ataması hususunda da uzun vadeli plan ve programlar yapılmalı, geçici çözümler olmamalıdır. Edebiyat Fakülteleri de dâhil olmak üzere, Formasyon Eğitimi, öğretmen yetiştirme ve istihdamında arz talep dengesi olmalı, yani öğretmen adayları için kontenjan ve istihdam doğru orantı içinde olmalıdır. Eğer politikalar istihdam problemini çözebilir ve organize bir hale getirebilirlerse İngilizce bölümlerinde eğitim alan öğrencilerin eğitim hayatları sürecinde oluşan kaygıları ortadan kalkmış olur. Özel eğitim kurumlarında görev yapan öğretmenlerin ise çalışma şartlarının iyileştirilmesi ve kendilerini daha güvende hissetmelerini sağlayacak tedbirlerin alınması gerekmektedir. Eğitim Fakülteleri ve Edebiyat Fakültelerinde öğrenim gören öğrenciler için başka alanlarda da uzman olmalarını sağlayacak çeşitli seçmeli derslerin verilmesi ve bunun diplomalarında belirtilmesi gerekmektedir. Son olarak da öğrencilerimiz daha ilköğrenime başladığı andan itibaren kabiliyetlerinin ortaya çıkarılmasını sağlanması ve ileride de okullardaki rehberlik hizmetleri vasıtasıyla, yetenekleri ve istekleri doğrultusunda onların meslek seçimleri konusunda yönlendirilmeleri, istihdam problemlerinin çözümünde önemli bir adım olacaktır.

\section{KAYNAKLAR}

Abazaoglu, i..(2014). Türkiyenin Öğretmen Profili. Turkish Studies - International Periodical For The Languages, Literature and History of Turkish or Turkic. Volume 9/2 Winter 2014, p. 1-20, Ankara.

Bayyurt, Y. ve Akcan, S. (2014). Türkiye'deki Yabancı Dil Eğitimi Üzerine Görüş ve Düşünceler. Boğaziçi Üniversitesi, 3. Ulusal Yabancı Dil Eğitimi Kurultayından Seçkiler.,23-24 Ekim 2014, İstanbul

Atmaca, H.(2013). Almanca, Bölümlerinde Okuyan Öğretmen Adaylarının Mesleki Kaygıları. Fransızca ve Ingilizce öğretmenliği Turkish Studies - International Periodical For The Languages, Literature and History of Turkish or Turkic Volume 8/10 Fall 2013, p. 67-76, Ankara.

Brad, R. (1994). Eleştirel Düşünme Becerilerini Öğretme. (Çev: Güzin Büyükkurt). Eğitim ve Bilim, 18 (91):45-49. 
Branch, B., J. (2000). The Relationship Among Critical Thinking, Clinical Decision Making, and Clinical Practica: A Comparative Study. Universty of Idaho PhD Thesis.

Çeliköz, N. ve Çetin, F. (2004).“Anadolu Öğretmen Lisesi Öğrencilerinin Öğretmenlik Mesleğine Yönelik Tutumlarını Etkileyen Etmenler", Milli Eğitim Dergisi,Sayı 162, ss.160-167

Devlet Planlama Teşkilatı (2009). Beş Yıllık Kalkınma Planları, http://ekutup.dpt. gov.tr/plan/plan.asp web adresinden 20 Mart 2015 tarihinde yararlanılmıştır.

Doğan, T. ve Çoban, A. E. (2009).“Eğitim Fakültesi Öğrencilerinin Öğretmenlik Mesleğine Yönelik Tutumları ile Kaygı Düzeyleri Arasındaki illişkinin İncelenmesi”, Eğitim ve Bilim, Cilt 34, Sayı 153, ss.157-168

Halpern, D. F. (1993). Assessing The Effectiveness of Critic-Thinking Instruction. The Journal of General Education. Vol.42, No:4, 338-353.

Inal, D. ve Özdemir E. (2015). Re/Considering the English Language Teacher Education Programs in Turkey from an EFL Standpoint: What do the Academia, Pre-service and InService Teachers Think? Y. Bayyurt ve S. Akcan (Haz), Current Perspectives on Pedagogy for English as Lingua Franca (ss. 135-152). Berlin: De Gruyter.

Karadeniz, Y., Demir, S. B.(2010). Sözleşmeli öğretmenlik uygulamasının değerlendirilmesi. Ondokuz Mayıs Üniversitesi Eğitim Fakültesi Dergisi, 29(2), 55-57.

MEB. (2016) http://personel.meb.gov.tr/sayisal veriler.asp?ID=207, 25 Nisan 2016 tarihinde erişilmiştir

Oktay, H.(2012). Türkiye'de öğretmen istihdamında Yaşanan sorunlar. Yayınlanmamış Yüksek Lisans Tezi, Dokuz Eylül Üniversitesi Eğitim Bilimleri Enstitüsü, İzmir.

Özoğlu, M.(2010). Türkiye'de öğretmen yetiştirme sisteminin sorunları, Ankara: Seta Analiz Yayınları.

Paul, R. W., L. Elder, (2001). Critical Thinking: Tools for Taking Charge of Your Learning and Your Life. Upper Saddle River, Nj: Prentice Hall.

Semerci, N.(2000). Kritik düşünme ölçeği. Eğitim ve Bilim. Cilt:25. Sayı116. S:23-26

Uygun, S. (2010). Türkiye'de öğretmen adaylarının seçimi ile ilgili bazı uygulamaların tarihsel analizi. GÜ, Gazi Eğitim Fakültesi Dergisi, 30, (3). 707-730.

Yıldız, G. (2005), Türkiye'de öğretmen yetiştirme ve istihdam durumu, Eğitimde Reform ve Finans Sorunu Sempozyumu. (16-17 Nisan 2007). Isparta: Süleyman Demirel Üniversitesi.

Yıldırım, A. ve Şimşek, H. (2013). Sosyal Bilimlerde Nitel Araştırma Yöntemleri. Ankara: Seçkin. 
This paper is about a qualitative study and will concern and raise the matter of employment of the students who graduate from the departments of English in Turkey. It is mentioned partly teacher training from the past in Turkey. As far as we know, we have a lot of Universities- state or private. Unemployment factor for today is becoming one of the crucial issues, since the numbers of graduates do not coincide with the demanded positions. Universities graduate more students and they don't consider the conditions of state and private sectors in our country. All the same, the students, who study at English Language and Literature and in English Language teaching departments, have some problems of employment. In this paper, we will try to define the main reasons of difficulties in finding job and try to find remedies some of the ways of solving this issue.

When we go back as far as 1980s in Turkey, there were no problems of appointments of English teacher candidates -graduates of educational and letters faculties, for State schools. And by their own wish they worked in private sectors such as private courses, schools, banking, interpreters, translators, so on and so forth. After the year of 2000 , there started to appear some problems about teacher employment for State Schools. As it has been explained, before these years, everybody was appointed, who completed related four-year faculty and whoever wanted, without any exam.

In the years of 2000, KPSS (State Personnel Selection Exam) were started to apply for teacher appointments. This situation caused to become a lot of stress and anxiety for unassigned teacher candidates and senior students of universities. Including students who graduated from English Departments, encountered appointment problems. Moreover, except from faculty of education, giving "pedagogical formation training" and appointing the graduated students from faculty of letters, make a bit more difficult the issue for teacher candidates who expects appointment for state schools. All the more, a lot of teachers couldn't be appointed, so, many teachers started to teach in private sectors, with heavy working conditions and low salary. All the same, the teacher candidates' first selection was to be a teacher in one of the states' schools due to better conditions, than private sector.

About the years of 2010 , we see to stay up to date the matter of employment. While the number of graduated students from such departments as pre-school teaching and psychological counseling and guidance are fewer in number than need for teachers in these fields, there are not many appointments although there are many graduated students from such departments as Physics, Geography, German and even English teaching.

The students worry about their future just after the registration for the department and although they study at the Philology Department they want to have Pegagogical Formation Certificate to teach so that they will have an anxiety problem of unemployment after graduation. Today ten thousands of the teacher candidates wait for appointment by the state. Because of limited appointment vacancies, the schools try to provide the teacher needs with part time or paid teachers.

The aim of this study is to define the ideas of the graduate students of English Departments by means of a qualitative study. It was used a qualitative method and case study in the work. The qualitative case study is the research of one or more cases in details. The study group of the research is twenty one undergraduate students of English Language and Literature Department, Karabuk University.

The question of "what are the problems of employment after graduation?", were asked to students. There were 5 male and 16 female students. And their answers were compiled as in the following.

Tablo 1.

\begin{tabular}{lc} 
Istihdamla ilgili Beklentiler & \\
\hline Beklentiler & Sayı \\
Öğretmenlik (Devlette) & 13 \\
Öğretmenlik (Özel sektörde) & 3 \\
Akademisyenlik & 4 \\
Fikrim yok & 1 \\
Toplam & $\mathbf{2 1}$
\end{tabular}



students.

It was done easy reachable exemplification and the application was directed towards voluntary

At the end of the experiment and evaluation of the subjects' papers we reached the following conclusions;

- Long plans and programs should be made about teacher assignment and the way out must be stable.

- The balance must be among the supply and demand on "pedagogical formation training", teacher training, and the employment. So, quota and employment must be in direct proportion for teacher candidates.

- English Teachers who working in private schools and sectors must to feel safe in the viewpoint of job guarantee, and their working conditions should be revised and authorities must take precautions.

- Students study in the faculties of education and faculties of letters should take more optional courses to be a specialist in any of other branches and this issue should be noted on their diploma.

- When our students even start the primary education, step by step, should be grouped according to their abilities and wishes in time, and they should be guided by the guidance services of the schools about selecting their future careers. 